\title{
The Resting-State Pulse-Respiration Quotient of Humans: Lognormally Distributed and Centered Around a Value of Four
}

\author{
F. SCHOLKMANN ${ }^{1,2}$, H. ZOHDI ${ }^{1}$, U. WOLF $^{1}$ \\ ${ }^{1}$ University of Bern, Institute of Complementary and Integrative Medicine, Bern, Switzerland, \\ ${ }^{2}$ Biomedical Optics Research Laboratory, Department of Neonatology, University Hospital Zurich, \\ University of Zurich, Zurich, Switzerland
}

Received June 13, 2019

Accepted July 31, 2019

Epub Ahead of Print October 25, 2019

\begin{abstract}
Summary
The pulse-respiration quotient (heart rate divided by the respiration rate, $P R Q=H R / R R$ ) is a parameter capturing the complex state of cardiorespiratory interactions. We analysed 482 single PRQ values obtained from measurement on 134 healthy adult subjects (49 men, 85 women, age: $24.7 \pm 3.4$, range: $20-46$ years) during rest. We found that the distribution of PRQ values (i) has a global maximum at around a value of 4 (median: 4.19) and (ii) follows a lognormal distribution function. A multimodality of the distribution, associated with several PRQ attractor states was not detected by our group-level based analysis. In summary, our analysis shows that in healthy humans the resting-state PRQ is around 4 and lognormally distributed. This finding supports claims about the special role of the 4 to 1 cardiorespiratory coupling in particular and the PRQ in general for physiological and medical views and applications. To the best of our knowledge, our study is the largest conducted so far in healthy adult humans about reference values of the PRQ during a resting-state at day.
\end{abstract}

\section{Key words}

Pulse-respiration quotient • PRQ • Cardiorespiratory interaction • Cardiorespiratory coupling

\section{Corresponding author}

F. Scholkmann, University of Bern, Institute of Complementary and Integrative Medicine, Fabrikstrasse 8, 3012 Bern, Switzerland. E-mail: Felix.Scholkmann@ikim.unibe.ch
Two intrinsic oscillatory processes accompany each moment of a living human being: cardiac activity and respiration. Both oscillations are locally triggered but regulated in a complex way as best represented by a nonlinear dynamical system based on two weakly coupled oscillators that are coupled by several structural and functional types of cardiorespiratory interactions, leading to emergent cardiorespiratory coupling phenomena (Benarroch 2018, Dick et al. 2014, Elstad et al. 2018, Krause et al. 2017, Lotrič and Stefanovska 2000, Moser et al. 2008, Schulz et al. 2013, Valenza et al. 2016). Such a cardiorespiratory coupling phenomenon is that the heart rate $(\mathrm{HR})$ and the respiration rate $(\mathrm{RR})$ have a specific frequency relationship. As recently reviewed by our group (Scholkmann and Wolf 2019), this relationship is given by dividing the heart rate (HR) by the respiration rate (RR), resulting in the pulse-respiration quotient $(\mathrm{PRQ}=\mathrm{HR} / \mathrm{RR})$. The PRQ in humans is of physiological relevance and depends mainly on the age, sex and individual physiological constitution of the subject, as well as on the time-of measurement (linked to the chronobiological state), physical activity, psychophysical and cognitive activity, and body posture (Scholkmann and Wolf 2019).

Two special features of the PRQ are that (i) in the resting-state of a healthy human (preferably during night, or during resting-periods at day), the PRQ tends to have a value of 4 , i.e. a state where the heart beats four times during one breathing cycle (Bettermann et al. 2000, Gutenbrunner and Hildebrandt 1998, Steiner 1989), and 
that (ii) the PRQ is not normally distributed but seems to follow a lognormal distribution (Scholkmann and Wolf 2019). Furthermore, there are reports indicating that the PRQ tends to favour integer values (a quantization) due to an in-phase cardiorespiratory coupling effect (termed cardiorespiratory coordination) with preferred values of the harmonic ratios $n / m$ with $n=3-6$ and $m=1$ while $n$ and $m$ represent the numerator and denominator of the equation $\mathrm{PRQ}=\mathrm{HR} / \mathrm{RR}=n / m$ (Bettermann et al. 2000, Bettermann et al. 2001, Bettermann et al 2002, Scholkmann and Wolf 2019). The relationship between the HR and RR is thus not random but is an emergent property as a result of complex cardiorespiratory interactions. A PRQ of 4 can be regarded as an attractor state that is approached during resting-conditions, while other attractor states are at other harmonic ratios (but less pronounced).

The aim of the present work was to evaluate these three assertions, i.e. the preference of the restingstate PRQ showing values around 4, being lognormally distributed and also exhibiting a quantization of values with preferences around integers. To this end, a large data set of own measurements has been analysed that was obtained during a systemic physiology augmented functional near-infrared spectroscopy (SPA-fNIRS) study conducted at our institute. The data set comprised of resting-state measurement of HR and RR of subjects sitting on a chair in a darkened room and wearing a SPAfNIRS setup to measure brain and physiological activity. HR was measured with a device registering cardiac activity as well as continuous blood pressure (SOMNOtouch NIBP, SOMNOmedics GmbH, Randersacker, Germany; sampling rate: $4 \mathrm{~Hz}$ ). RR was measured with a patient monitor with a capnography module (LifeSense, Nonin Medical, Plymouth, MN, USA; sampling rate: $1 \mathrm{~Hz}$ ). The capnograph was connected to a small tube with an open end attached below the nostrils of the subject. The tube attached did not influence the breathing of the subject nor caused any discomfort. The PRQ was determined by averaging the HR and RR measurement for each experiment for a recording period of $5 \mathrm{~min}$ (i.e. last $5 \mathrm{~min}$ of the baseline phase). It was ensured that the subjects were in an awake resting-state during the measurements. Measurements were conducted in 134 healthy subjects (49 men, 85 women, age: $24.7 \pm 3.4$, range: $20-46$ years) and were repeated 2-4 times for each subject (on different days) resulting in 482 single measurements and thus single resting-state PRQ values. The subjects did not have an acute disease nor a chronic disease affecting the cardiovascular, cardiorespiratory or neuronal system. The body mass index of the population was $22.08 \pm 2.42$ (range: 17.54-31.22) showing that the population consisted of subjects of normal weight.

The measured raw signals were processed in Matlab (R2017a, MathWorks, Inc., MA, USA) and the statistical analysis was conducted in $\mathrm{R}$ (version 3.4.4) (R Core Team 2019). For the analysis of the data distribution, the R package "fitdistrplus" (DelignetteMuller and Dutang 2015) was employed.

In order to investigate assertion 1 (i.e. the prevalence of the resting-state PRQ showing values around 4) and assertion 2 (i.e. the lognormal distribution of the data), the PRQ data were analysed with a Cullen and Frey plot (skewness-kurtosis plot) (Cullen and Frey 1999) involving a nonparametric bootstrap procedure (number of bootstraps: 5000) to take into account the uncertainty in estimating the kurtosis and skewness (Efron and Tibshirani 1994). The empirical distribution of PRQ values was compared with the following distributions: normal, uniform, exponential, logistic, beta, lognormal and gamma. Fig. 1a shows that the lognormal distribution is the most suitable one explaining the empirical PRQ distribution. To further corroborate this finding, the goodness-of-fit was evaluated by fitting a lognormal distribution to the data, comparing the empirical and theoretical cumulative density functions (CDFs), creating a Q-Q plot (theoretical vs. empirical quantiles) and a P-P plot (fitted distribution function vs. empirical distribution function). Because the Cullen and Frey plot analysis found the lognormal distribution representing the empirical PRQ distribution at best, and since the Weibull distribution is similar to the lognormal one (Cain 2002, Kundu and Manglick 2004), the goodness-of-fit was evaluated for the lognormal and Weibull distribution. The analysis showed that the lognormal distribution fits the PRQ data better than the Weibull distribution (loglikelihood: -627.7287, Akaike information criterion (AIC): 1259.457, Bayesian information criterion (BIC): 1267.813 vs. -684.2619 , AIC: 1372.524, BIC: 1380.88). The fit with the lognormal distribution (Fig. 2c) gave a median PRQ value of 4.19 with a skewness of the distribution of 1.00 and a kurtosis of 5.30 , respectively. That the lognormal distribution fits the data well can be also inferred by visually comparing the empirical fit (density estimate) with the lognormal fit (Fig. 2a, c). Also the comparison with the empirical and theoretical CDFs (Fig. 2d), the 
Q-Q plot (Fig. 2e) and the P-P plot (Fig. 2f) support the finding that the PRQ data follow a lognormal distribution.

To evaluate assertion 3 (i.e. the quantization of PRQ values with preferences of integers), the following procedure was performed: each single PRQ value of the data set was compared to the next integer and the difference was calculated, resulting in $\triangle \mathrm{PRA}$ values $(\triangle \mathrm{PRA}=\mathrm{PRQ}-[\mathrm{PRQ}]$, with $[\cdot]$ the round-to-nearest integer operator), and the distribution of $\triangle P R Q$ values was analysed.
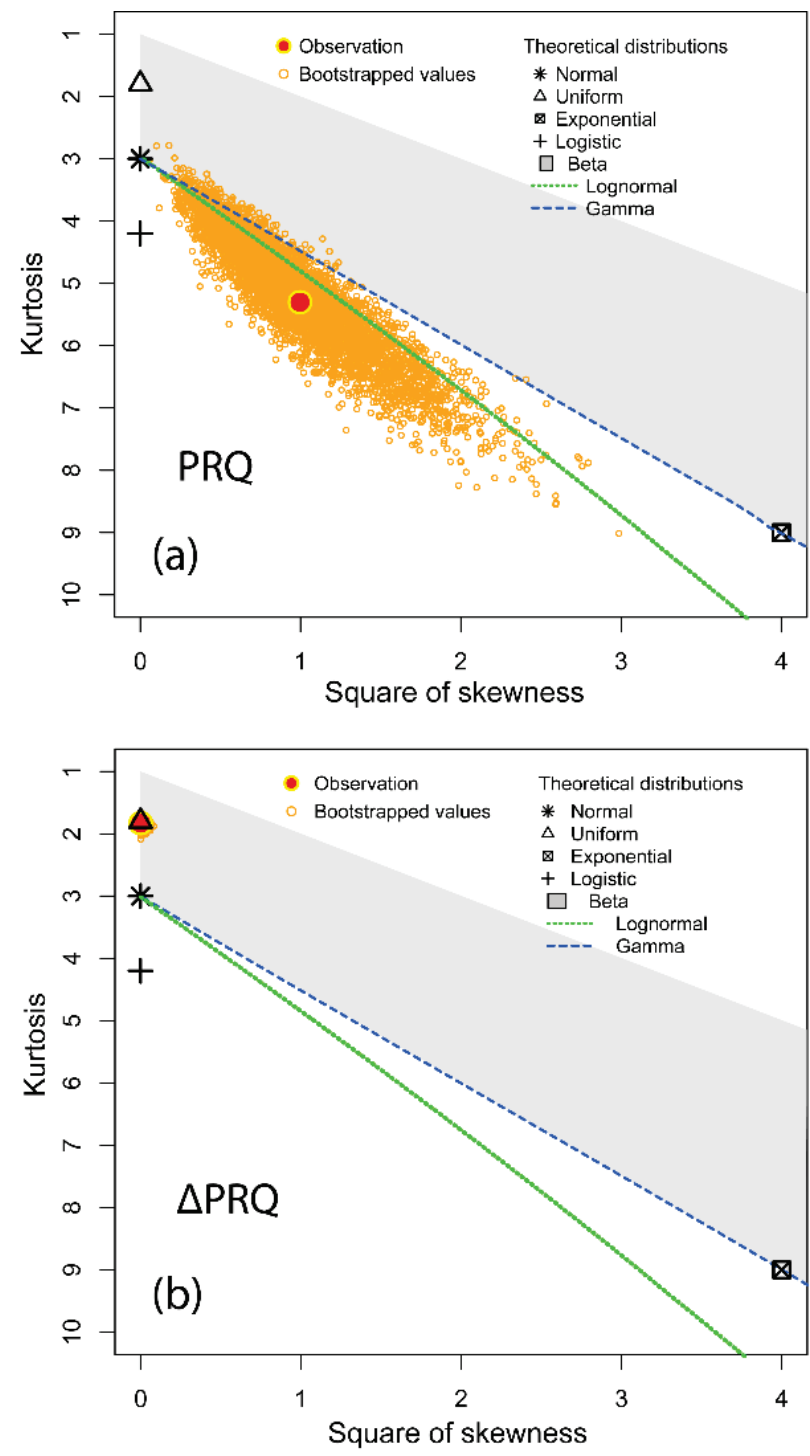

Fig. 1. Cullen and Frey plots for the $P R Q$ (a) and $\triangle P R Q$ (b) data. The analysis revealed that the distribution of $P R Q$ data is approximated at best by a lognormal distribution and the $\triangle P R Q$ data by a uniform one.

Since a quantization of PRQ values results in a distribution with preferred values of integers, the resulting $\triangle \mathrm{PRQ}$ distribution should have a clear maxima around 0 and should follow approximately a normal distribution. As Fig. $2 b$ shows, no preferred $\triangle P R Q$ value was evident from the distribution. The Cullen and Frey plot of the data (Fig. 1b) further showed that the data can be approximated at best with a uniform distribution and that a normal distribution does not fit the data well. Both results support the conclusion that no quantization of PRQ values was evident.

Our analysis thus confirmed assertion 1 and 2 that the resting-state PRQ on a group-level has a high probability of having a value of around 4 and being lognormally distributed. Our analysis thus agrees with the previous publications stating assertions 1 and 2, indicating the occurrence of cardiorespiratory coupling in the restingstate. Assertion 3 about the quantization of PRQ values (which would indicate a cardiorespiratory coordination) was not supported by our analysis. There are three main reasons for not finding the PRQ quantization according to our reasoning. First, it could be that the PRQ quantization is more/less pronounced in individual subjects and that a group-level analysis (as we did) is not able to detect it since the effect is weakened by our analysis approach. This aspect is especially significant since we calculated the PRQ value by dividing the median of the HR by the median of the PR (from the $5 \mathrm{~min}$ time-series) and not by calculating the instantaneous PRQ (from the 5 min time-series) and then taking the median of it. The second approach might be better characterizing the individual quantized PRQ states. Further research is needed to investigate this reasoning. Second, the PRQ quantization could be mainly better detected by analysing the PRQ values of an individual subject during a specific time-interval (during this interval, there might be a cardiorespiratory coupling preference, i.e. cardiorespiratory coordination, with integer PRQ values, as indicated by previous works). Calculating an average over all PRQ values for the interval (as we did) might weaken the PRQ quantization effect in the data since only the average of the PRQ is taken into account in the final group-level analysis and not possible additional maxima of the PRQ distribution. This conclusion is supported for example by the study of Bettermann et al. (2001) who detected a PRQ quantization when first analysing the individual PRQ distributions for each experiment and then performing the group-average; with this approach, the presence of local maxima in the PRQ distribution at values of 4, 3, 2 and 5 in nightly resting-stated PRQ values of women with metastasized breast cancer was detected. According to this finding, the PRQ quantization thus might 
Distribution of $P R Q$ values

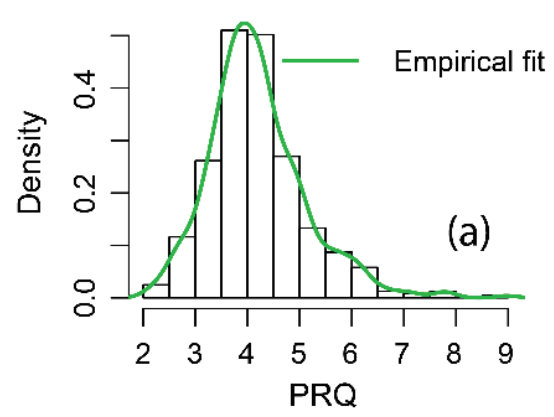

Distribution of $\triangle P R Q$ values

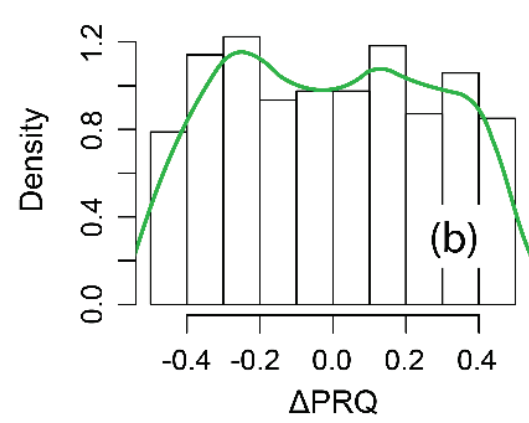

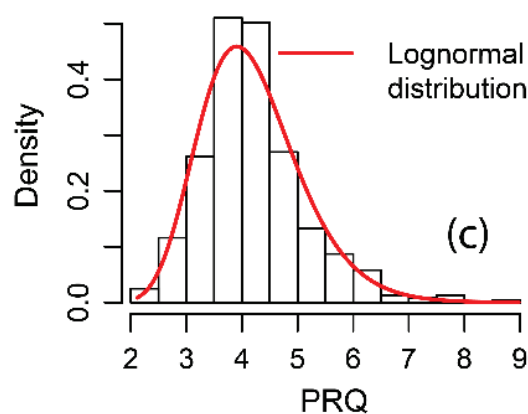

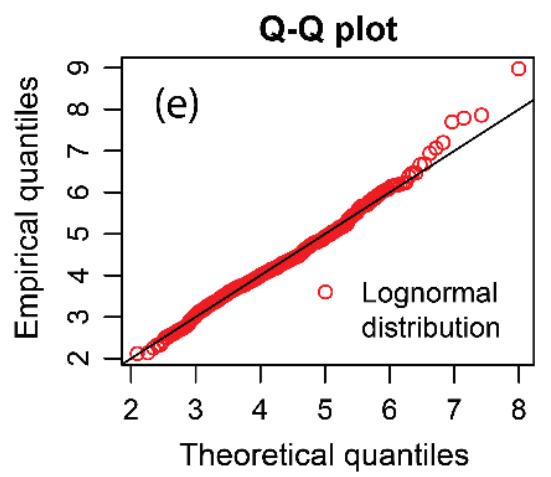

Empirical and theoretical CDFs
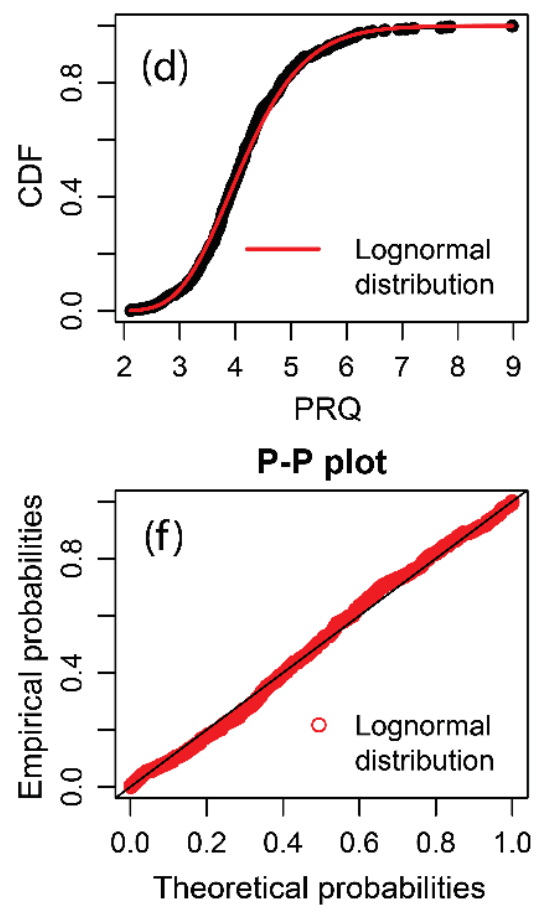

Fig. 2. (a, b) Comparison of histograms of $P R Q$ and $\triangle P R Q$ values with density estimations. (c-f) Evaluation of the goodness-of-fit for fitting the PRQ distribution with a lognormal distribution. CDFs: cumulative density functions.

be also related to the health state of a subject, and since our study included healthy young subjects, the occurrence of this effect might be less likely. Third, the PRQ quantization might be only an artefact or phenomena that is happening only occasionally so that a generalization is unjustified. According to our assessment, the most likely conclusions seem to be the first and second ones. Further research is needed, and will be conducted by us, to clarify this aspect.

Our finding that the resting-state PRQ of human adults is indeed around 4 is not only of interest for basic human physiology but has also medical relevance since deviations from this norm might be associated with pathophysiological processes. Indeed, the usefulness of evaluating the resting-state PRQ in patients for diagnosis and disease monitoring has been already shown (Bettermann et al. 2001, Göbels 2014, Heckmann 2001, Hildebrandt 1960, 1980, 1985, 2009, Kümmell and Heckmann 1987, Suchantke 1951, Weckenmann 1975, 1981). For example, a tendency of resting-state PRQ to be closer to 4 during the course of an influenza disease has been documented (Müller 1972). A state of PRQ $\approx 4$ has been termed "PRQ normalization", associated with an optimal functioning of the cardiovascular system a balanced state of the autonomic nervous system, being relevant for and being correlated with a healthy physiological state of a human (Hildebrandt 1997, Scholkmann and Wolf 2019). The significance of $\mathrm{PRQ} \approx 4$ is highlighted by the fact that the resting-state PRQ is also around 4.5 for all mammals and thus is not following an algometric scaling law as the HR or RR (Schmidt-Nielsen 1984, Stahl 1967).

The finding about the lognormality of the PRQ distribution is important for future studies using the PRQ since the statistical analysis of PRQ values thus needs to be treated accordingly, i.e. taking the log of the PRQ value is necessary to transform the data to a normal distribution so that the requirements of the classical statistical test are fulfilled.

To the best of our knowledge, our study is the largest conducted so far in healthy adult humans about reference values of the PRQ during a resting-state at day.

\section{Conflict of Interest}

There is no conflict of interest.

\section{Acknowledgements}

This work was supported by the grant CST grants 253 CST (2016, 2017) and 355 CST (2018), and the SAGST grant P12117. The authors wish to thank John Folkes for his kind assistance in English language revision and proofreading. 


\section{References}

BENARROCH EE: Brainstem integration of arousal, sleep, cardiovascular, and respiratory control. Neurology 91: 958-966, 2018.

BETTERMANN H, CYSARZ D, VAN LEEUWEN P: Detecting cardiorespiratory coordination by respiratory pattern analysis of heart period dynamics-the musical rhythm approach. Int J Bif Chaos 10: 2349-2360, 2000.

BETTERMANN H, KRÖZ M, GIRKE M, HECKMANN C: Heart rate dynamics and cardiorespiratory coordination in diabetic and breast cancer patients. Clinical Physiol 21: 411-420, 2001.

BETTERMANN H, VON BONIN D., FRÜHWIRTH M, CYSARZ D, MOSER M. Effects of speech therapy with poetry on heart rate rhythmicity and cardiorespiratory coordination. Int J Cardiol 84: 77-88, 2002.

CAIN SR: Distinguishing between lognormal and Weibull distributions [time-to-failure data]. IEEE Transactions on Reliability 51: 32-38, 2002.

CULLEN AC, FREY HC: Probabilistic techniques in exposure assessment. Springer, USA, 1999.

DELIGNETTE-MULLER ML, DUTANG C: Fitdistrplus: An R package for fitting distributions. J Stat Software 64: $1-34,2015$

DICK TE, HSIEH YH, DHINGRA RR, BAEKEY DM, GALAN RF, WEHRWEIN R, MORRIS KF: Cardiorespiratory coupling: common rhythms in cardiac, sympathetic, and respiratory activities. Prog Brain Res 209: 191-205, 2014.

EFRON B, TIBSHIRANI RJ: An Introduction to the Bootstrap (Chapman \& Hall), 1994.

ELSTAD M, O’CALLAGHAN EL, SMITH AJ, BEN-TAL A, RAMACHANDRA R: Cardiorespiratory interactions in humans and animals: rhythms for life. Am J Physiol Heart Circ Physiol 315: H6-H17. 2018.

GÖBELS R, ALLMEER C: Die Behandlung mit Rhythmischer Massage bei einer Patientin mit Mammakarzinom. (in German) Der Merkurstab 67: 126-135, 2014.

GUTENBRUNNER C., HILDEBRANDT G: Handbuch der Balneologie und medizinischen Klimatologie. (in German) Springer, Berling, Heidelberg, 1998.

HECKMANN C: Zur Frage der klinischen Bedeutung des Puls-Atem-Quotienten (QP/A). (in German) Der Merkurstab 54: 13-24, 2001.

HILDEBRANDT G: Die rhythmische Funktionsordnung von Puls und Atmung. (in German) Z. angew. BäderKlimaheilkunde 7: 533-615, 1960.

HILDEBRANDT G: Chronobiological aspects of cure treatment. J Jpn Soc Balneol Climatol Phys Med 44: 1-37, 1980.

HILDEBRANDT G: Die Bedeutung rhythmischer Phänomene für Diagnose und Therapie. (in German) Beitr. Erweit. Heilkunst geisteswiss. Erkenntnissen 38: 8-24, 1985.

HILDEBRANDT G: Rhythmusforschung als Aufgabe einer anthroposophisch-goetheanischen Naturwissenschaft. (in German) Der Merkurstab 50: 329-336, 1997.

HILDEBRANDT G: Untersuchungen über die rhythmische Funktionsordnung von Pule und Atem. Acta Medica Scandinavica 152: 175-184, 2009.

KRAUSE H, KRAEMER JF, PENZEL T, KURTHS J, WESSEL N: On the difference of cardiorespiratory synchronisation and coordination. Chaos 27: 093933, 2017.

KÜMMELL HC, HECKMANN C: Herzinfarkt und rhythmisches System. (in German) Der Merkurstab 40: 15-27, 1987.

KUNDU D, MANGLICK A. Discriminating between the Weibull and log-normal distributions. Naval Research Logistics 51: 893-905, 2004.

LOTRIČ MB, STEFANOVSKA A: Synchronization and modulation in the human cardiorespiratory system. Physica A 283: 451-461, 2000.

MOSER M, LEHOFER M, HILDEBRANDT G, VOICA M, EGNER S, KENNER T: Phase- and frequency coordination of cardiac and respiratory function. Biol Rhytm Res 26: 100-111, 2008.

MÜLLER H: Der Puls-Atem-Quotient. Beobachtungen über die Verwendbarkeit in der Praxis. Beitr. Erweit. Heilkunst geisteswiss. Erkenntnissen 25: 1-10, 1972.

SCHMIDT-NIELSEN K: Scaling: Why is animal size so important? Cambridge University Press, Cambridge, UK, 1984. 
SCHOLKMANN F, WOLF U: The pulse-respiration quotient: A powerful but untapped parameter for modern studies about human physiology and pathophysiology. Front Physiol 10: 371, 2019,

SCHULZ S, ADOCHIEI F-C, EDU I-R, SCHROEDER R, CORSTIN H, BÄR, K-J, VOSS A: Cardiovascular and cardiorespiratory coupling analyses: a review. Philos Trans A Math Phys Eng Sci 371: 20120191-91, 2013.

STAHL WR: Scaling of respiratory variables in mammals. J Appl Physiol 22: 453-460, 1967.

STEINER R: Physiologisch-therapeutisches auf Grundlage der Geisteswissenschaft. Zur Therapie und Hygiene. (in German) Rudolf Steiner Verlag, Dornach, Schweiz, 1989.

SUCHANTKE G: Puls und Atem; Versuch einer Funktions-Erkenntnis des rhythmischen Menschen in Klinik und Praxis. Der Merkurstab 4: 105-112, 1951.

R CORE TEAM: A language and environment for statistical computing. R Foundation for Statistical Computing, Vienna, Austria, 2018. https://www.R-project.org/.

VALENZA G, TOSCHI N, BARBIERI R: Uncovering brain-heart information through advanced signal and image processing. Philos Trans A Math Phys Eng Sci 374: 2067, 2016.

WECKENMANN M: Der Puls-Atem-Quotient der orthostatisch Stabilen und Labilen im stehen'. (in German) Basic Res Cardiol 70: 339-349, 1975.

WECKENMANN M: Blutdruck und rhythmische Parameter als abhängige Größen im Grenzbereich zwischen orthostatischer Stabilität und Labilität. (in German) Basic Res Cardiol 76: 211-223, 1981. 